Da samtlige andre tekstvidner til Låleoverleveringen er tryk og håndskrifter der kun indeholder denne tekst, er det desuden væsentligt at undersøge om ordsprogssamlingen har forbindelse til C 22's øvrige tekster. Dette kan vise sig særligt interessant fordi C 22 stammer fra Vadstenas klosterbibliotek.

Jeg regner med i et kommende arbejde at undersøge C 22 og hvad det kan sige om Lålesamlingens ældste overlevering.

Simon Skovgaard Boeck

\title{
Leonardo da Vinci
}

\section{Et utrykt essay af Sophus Claussen}

This paper presents a hitherto unpublished essay by the Danish symbolist poet Sophus Claussen (1865-1931). The essay entitled 'Leonardo da Vinci' was intended for the collection Løvetandsfnug ('dandelion fluff'), 1918, but was for unknown reasons omitted in the final edition. In the essay, Claussen recalls when, at the Uffizi Gallery in Florence in 1902-03, he saw a painting (perhaps by Leonardo da Vinci) depicting the Annunciation to the Blessed Virgin Mary. At the time, the Virgin Mary of the painting reminded Claussen of a young Danish girl with whom he had been hopelessly in love some ten years prior. The remembrance of this past experience, at the time of writing the essay in early or mid 1918, causes him to contemplate not only the artistic method of Leonardo, but also, more generally, the relationship between chastity and lust, nature and imitation, and art and science. 'Leonardo da Vinci' has never been described in the secondary sources on Claussen's work. It is, however, arguably both interesting and exemplary for its dual role as both a biographical and poetological lead in his essays and in his oeuvre as a whole.

Sophus Claussen (1865-1931) var en produktiv forfatter gennem en stor del af sit liv. Foruden digtbøger, romaner, skuespil og en enkelt novellesamling udgav han i aviser og tidsskrifter flere end 1500 enkeltstående tekster heriblandt artikler, anmeldelser og erindringsstykker. Nogle af de bedste af disse indgik siden i de to essaysamlinger: Løvetandsfnug (1918) og Foraarstaler (1927). Samlingerne består begge af fortrinsvis tidligere trykte tekster, men indeholder også nyskrevet materiale. Her skal præsenteres et nyskrevet essay, der oprindeligt var tiltænkt Løvetandsfnug, men som af uvisse årsager blev udeladt i den endelige redaktion. Essayet bærer titlen »Leonardo da Vinci« og er bevaret $\mathrm{i}$ Claussens arkiv på Det Kgl. Bibliotek i tre manuskriptvarianter: en renskrift, en kladde og et udkast. Det er antagelig skrevet i foråret el- 
ler sommeren 1918, altså kort før udgivelsen af bogen, der udkom d. 16. november ${ }^{1}$

Hvorfor Claussen har udeladt essayet i den endelige udgave, kan man kun gisne om. Det fremgår af indholdsfortegnelsen til kladden og må således have været medtænkt indtil forholdsvist sent $\mathrm{i}$ tilblivelsesprocessen. Det kan næppe være af pladshensyn, at han har fravalgt det. Bogen er produceret i oktavformat, altså med 16 sider pr. trykark. Sidste ark begynder på niendesidste side, hvilket levner tilstrækkelig plads til, at det korte essay burde have kunnet medtages, uden at man skulle have bekostet et yderligere ark. Når han alligevel har fravalgt det, kan det muligvis skyldes, at han har fundet dets hovedtanke for uudviklet. Teksten er rig, men også temmelig springende og notatagtig - selv efter Claussens standard. En mulighed er desuden, at essayets skildring af en ulykkelig forelskelse fra forfatterens ungdom har været problematisk. Historien er godt nok en genkommende inspiration i hans forfatterskab, men optræder andre steder i højere grad fiktionaliseret eller lyrisk symbolsk. Med Claussens tilbagevendende ægteskabelige kriser in mente kan det godt være, at han fandt det uklogt at medtage essayet i dets herværende form. ${ }^{2}$ På trods af dets lidt ufærdige status har »Leonardo da Vinci« dog fine litterære kvaliteter og er interessant både biografisk og poetologisk. Det indskriver sig udmærket i Løvetandsfnugs kollageagtige fremstillingsform. Samlingen er sammensat af genremæssigt meget forskellige tekster, lige fra ungdomserindringer til rejsebeskrivelser, taler, foredrag, digte og noveller. Claussens svigersøn og biograf Ernest Frandsen kalder den for en slags »Levned og Meninger« med genlyd af Johannes Ewalds selvbiografi (Frandsen 1950: 2, 200). Men hvor Ewalds erindringstekst udmærker sig ved sine indlejrede digressioner og moralske bekendelser, og som sådan kan tolkes som en hybrid mellem konfession, selvbiografi og roman, beskæftiger den sig ikke på samme måde som Claussens essays med den kunstneriske og poetiske tradition. ${ }^{3}$

1 Ingen af manuskriptkilderne er daterede, men omslaget til den notesbog, hvori udkastet står skrevet, prydes af en blyanttegning dateret: »Marts 1918« (Det Kgl. Bibliotek, NKS 1340, $8^{\circ}:$ nr. 74).

2 Bo Hakon Jørgensen og Jan Sand Sørensen dokumenterer med kilde i Claussens dagbog, hvordan forholdet til hustruen fra begyndelsen havde været besværligt, og hævder ligefrem, at: »Ægteskabet, der allerede længere havde været under opløsning, var i 1917 (...) på vej til åben separation « (Jørgensen og Sørensen 1977: 61).

3 For en karakteristik af Ewalds Levnet og Meeninger som hybridtekst se Peer E. Sørensen 1998. 
Claussen indskyder i Løvetandsfnug gennemgående poetologiske og kunstkritiske refleksioner også i de selvbiografiske og fiktive tekster. Ofte citerer og reflekterer han over sit eget forfatterskab så vel som over samtidige og tidligere generationers digtere, især Charles Baudelaire, Paul Verlaine og Heinrich Heine, og ikke sjældent kommer refleksionerne til at danne udgangspunkt for en mere overordnet holdning til kunsten og livet. For denne praksis er det genfundne essay eksemplarisk, selvom emnet her ikke i første omgang er digtningen, men malerkunsten. Teksten begynder med en skildring af forfatterens besøg på kunstmuseet Galleria degli Uffizi i Firenze under Claussens anden store italiensrejse i 1902-03. Her ser han et maleri forestillende Marias bebudelse, som havde været tilskrevet Leonardo da Vinci, om end dette siden angiveligt var blevet tilbagevist. Maleriets Maria giver, med sit yndefulde, knejsende hoved, Claussen mindelser om hans tidligere italiensrejse ca. 10 år forinden og om »en lille, dansk stivnakke«, som han dengang havde forelsket sig håbløst i. Nu får gensynet med maleriet ham til at reflektere over Leonardos kunstholdning, der i mange tilfælde forekommer forfatteren »som Tanker af hans egen Avl«. I hvad Claussen kalder Leonardos »glasklare Tvetydighed «, genfinder han en kunstholdning, der minder forbløffende om hans egen livsanskuelse. Leonardo maler altid skønheden, om end sjældent ublandet. Han »forstaar en Sjæls guddommelige Ynde, men kender tillige den dobbelte Ynde ved det, som lige antydes «. Denne antydningens kunst forbinder Claussen med en form for uskyldstab. Maria er hos Leonardo den eneste, der er ren. Selv »Seraferne (...) kender Synden og dens Farve«, som det hedder. Uskyldstabet har desuden konsekvenser også for forfatterens oplevelse af kærligheden. Hans forståelse af Leonardos dobbelthed får ham videre til at reflektere over forholdet til sin ungdomselskede, som han oplevede som lige så bly og ærbar som erotisk dragende. Hun ejede både »Englenes kyske Erfaring og Kurtisanens søde smil«. Det er denne modsætning, Claussen siden har kæmpet med at få greb om, og som gør, at han endnu ikke er nået til afklaring om, hvilket af naturens klassiske symboler, han skal beskrive hende med: en rose eller en viol. Men han ved dog, at der i erindringen om hende ligger en konflikt, som kan give stof til en bog. Hvis han blot kunne skrive den.

Den biografiske baggrund for »Leonardo da Vinci«-essayet er Claussens ulykkelige kærlighedshistorie fra hans ophold i Paris 189294. Den 28-årige forfatter var efter fejlslagne jurastudier og sporadiske ansættelser ved forskellige provinsaviser rejst til den franske hovedstad for at lære sproget og suge kunstnerisk næring i det symbolistiske miljø omkring digterne Paul Verlaine og Stéphane Mallarmé. Her mødte han 
i begyndelsen af 1893 københavnske Karen Topsøe - ældste datter af forfatter og journalist Vilhelm Topsøe - som han friede til, men blev afvist (jf. Zeruneith 1992: 160 ff.). I første omgang var afvisningen så lidelsesfyldt, at han end ikke kunne blive i Paris, hvorfor han i januar 1894 rejste videre til Italien med ophold i bl.a. Genova, Siena, Rom, Napoli, Rapallo og altså Firenze. Den umiddelbare smerte hudflettede dog kun Claussen kortvarigt. Allerede i midten af juli flyttede han sammen med en 25-årig gift, italiensk kvinde, Clara Robinson, med hvem han levede i næsten to måneder, og efter hjemkomsten til Danmark giftede han sig endelig i 1896 med sin tidligere forlovede fra Horsens, Anna Christensen. Men historien om forfatterens store forelskelse i Paris skulle alligevel blive skelsættende for hans selvforståelse og selvudvikling i mange år efter. Det er da også denne historie, som han ifølge essayet endnu en gang mindes, da han betragter Leonardos malerier i Galleria degli Uffizi på sin anden italiensrejse, nu sammen med Anna og deres ældste datter, Ilse.

Claussen bearbejder erindringen om Karen Topsøe kunstnerisk gentagne gange i sit forfatterskab, men oftest anderledes poetisk end i essayet her. Andre steder fiktionaliseres hun eller beskrives mere antydende. I rejseromanen Valfart (1896) kaldes hun eksempelvis Celimène og er en forfængelig fransk kvinde med »dobbeltbundede Øjne« og med en mund, der er som et kløverblad, »kruset og fyldigt, sødtduftende«, men alligevel »fint og kysk som en dugget, nordisk Morgen « (Claussen 1990: 161). ${ }^{4}$ I »Leonardo da Vinci« kaldes hun ligefremt »Københavnerinden« - om end hun sammenlignes med både Gretchen og det såkaldte 'lillemenneske' fra Goethes Faust, og så altså selveste »Guds Moder«. ${ }^{5}$ Essayets sammenligning af »Købehavnerinden « med Maria er interessant, fordi den udgør et skæringspunkt mellem det biografiske og det poetologiske spor i Claussens værk. Den ungdomselskede i det i udgangspunktet selvbiografiske essay erindres som en faktisk person, men knyttes med mariabilledet an til et motiv, der varieres og udvikles i løbet af forfatterskabet, og som derved løsriver sig fra det biografiske. Maria identificeres hos Claussen på forskellig vis med en forening af det evige eller uskyldige

4 Den biografiske tolkning af Claussens ungdomskærligheds betydning for Valfart grundlægges af Aage Henriksen, som identificerer Celimène-figuren med forfatterens »første elskov, som hændte ham i Paris i året 1893« (1965: 106). Henriksen nævner dog ikke her Karen Topsøe ved navn.

5 Lillemennesket ('Homunculus') er i anden del af Goethes Faust et menneskelignende væsen, som bor i en glaskolbe, skabt af Fausts forskningsassistent, Wagner (Faust. Der Tragödie zweiter Teil, 2. akt, 1. 359 ff.). 
og det jordiske. I Valfart møder hovedpersonen som en erstatning for den tabte Celimène en ny kærlighed, der modsat hende ikke er karrig med at vise sin jordiske kærlighed. Hun minder ham om »Pavens Madonna« fra Michelangelos marmorgruppe i Peterskirken, som hun sidder »med Liget af den Korsfæstede tværs over det moderlige Skød« (ibid.: 223). På lignende måde modstilles Maria i det senere digt »Atomernes Oprør« (Heroica, 1925) med den gammeltestamentlige Eva, der kritiseres for at være gold og sætte sig op imod sin lykke. Maria derimod er, som den, der skal føde Guds søn, på samme tid ren og menneskelig. Hun betegnes som både »Jomfru og Moder og skyldfri og Kvinde med jordiske Klæder« (Claussen 1983: 140). Det er denne for Claussen så vitale Mariafigur, der altså nu får ham til at mindes sin ungdomselskede og reflektere videre over kunsten og digtningens væsen, da han atter i Firenze betragter det nævnte maleri.

Hvilket af Galleria degli Uffizi adskillige malerier af Marias bebudelse, Claussen har ladet sig inspirere af, kan ikke afgøres med sikkerhed. Noget taler for, at det kunne være det berømte Annunciazione fra ca. 1472-75, der i dag er almindeligt anerkendt som værende et af Leonardos tidligste hovedværker. Dets ophav var i samtiden omstridt, hvilket kan være grunden til, at Claussen mener, at det nu var »paavist ikke at være af Vinci« ${ }^{6}$ Om maleriets Maria er malet af Leonardo eller ej, er imidlertid ikke særlig væsentligt. Uanset hvad »forklarer [hun] visse Sætninger af ham, som jeg dengang søgte at indprente mig«, hævder Claussen. Disse sætninger fra Leonardos skrifter, som har fulgt ham siden hans første italiensrejse, giver anledning til en række centrale kunstkritiske og poetologiske refleksioner. Hos Leonardo finder Claussens et specielt syn på forholdet mellem naturen og mennesket, for eksempel når det om maleren hedder, at »en dirrende Fuglevinge lærer ham om Øjelaagets Bevægelse«, og »Af at betragte Blomsterne lærer han, hvorledes han skal male Hænderne«. Denne evne til at overskride skillelinjen mellem natur og menneske, som Claussen altså tilskriver Leonardo, afføder en kompleks situation, der uddyber og spejler en synsmåde, Claussen kan genkende fra sin egen praksis: at digtningen er et greb, der kan åbne for en større verden end naturalismens netop igennem den præcise naturgengivelse.

Claussen nævner i essayet muligheden for, at den grænseoverskridende synsmåde kan tjene som en udfordring af den traditionelle spaltning mel-

6 Af Galleria degli Uffizis udstillingskatalog fra 1891 fremgår det, at nogle kunstkritikere tilskrev maleriet Rodolfo del Ghirlandaio eller Lorenzo di Credi (Rigoni 1891: 220). 
lem videnskab og kunst. På den ene side billiger Claussen ikke de digtere, der forsøger at agere videnskabsmænd, og som han mener tager sig ud som »Circusnarre paa Stylter«. På den anden side afviser han ikke, at den inspirerede digter med en »genial Tænken« sommetider finder det, »som mislykkes for den pinlig grublende Forsker«. Essayet er et vigtigt eksempel på den særlige tillid, Claussen nærer til kunsten. Hans grundholdning er, at poesien og kunsten kan bidrage lige så meget til livet, som videnskaben kan, men at den gør det ud fra en væsensforskellig synsmåde. Kunstens styrke er, at den kan anskue verden fra mange sider samtidig. Den kan give fornemmelsen af det, Claussen i essayet kalder »det allestedsnærværende Liv, som røber sig lige klart i de mest ulige Former«. En dag vil han skrive om dette allestedsnærvær, forestiller han sig. Det skal være $i$ et digt, der på en gang indfanger naturen og mennesket - som $\mathrm{i} »$ samme Aandedræt kan nævne 'Jordens Blomst og Læbens Tale'«.' Dan Ringgaard beskriver i sin disputats om Claussens lyrik, rejsebøger og essayistik forfatterens tilgang som »ikke ulig kubismens: man ser kun det hele, hvis man ser alle steder fra på én gang « (Ringgaard 2000: 349). Det er denne tilgang, Løvetandsfnug med sine mangeartede genrer demonstrerer, og for hvilken det her fremdragne essay er eksemplarisk.

\section{Sophus Claussen: »Leonardo da Vinci« (1918)}

Et Tilfælde - det vil sige en lille Bog, som havde listet sig ned i min Sommerkuffert - har atter ført mig sammen med hin Italiener Leonardo da Vinci, der meget optog mine Tanker, da jeg gjorde min første italienske Rejse, med Ophold ved alle Kunstkamre og Museer.

Leonardos glasklare Tvetydighed er siden hine Herredage først i Halvfemserne ikke altid blevet hyldet af Udraaberne paa Kunstens nye Marked. Hans Kneb og Kunstgreb, saaledes som de afslører sig i hans Skrifter eller i den forsvundne og genfundne Mona Lisa, var ikke Malernes Forbillede paa »Indépendenterne« i Paris.

Men 10 Aar efter - da jeg altsaa vandrede i Uffizierne i Firenze og var meget mere latinsk end italiensk, mere romersk antik og hedensk end ren-

7 I udkastet til essayet angives det, at udtrykket stammer fra Claussens foredrag om moderne lyrik, svarende til det, der er trykt i Løvetandsfnug i afdelingen »Jord og Sjæl« (Det Kgl. Bibliotek, NKS 1340, $8^{\circ}$ : nr. 74). Udtrykket optræder imidlertid ikke her, ligesom Claussen heller aldrig fik skrevet et digt, hvori det indgår. 
næssancefrom - havde jeg altid et Udpluk af hans Kunstlærdomme ved Haanden og faldt i Staver over Billeder, som dengang blev tilskrevne og senere fraskrevne Vinci.

Blandt andet var jeg, maaske for Kærlighedens Skyld, af hele mit Hjerte indtaget $\mathrm{i}$ en Bebudelse, hvor en lille, stolt knejsende Maria modtager Englens: Hil dig, du Benaadede!

Jeg tilbad den lille Kvinde, for hendes Kyskhed og Strenghed, som paavirkede mig gretchenagtigt, det vil sige germansk og dog med et Præg af Aristokrati, der røber romansk Race, en Aandsbevidsthed let fattelig hos den Jomfru, der kaares til Guds Moder.

Samtidig frydede jeg mig udholdende og mandhaftigt over Karakteristikken i den rungende Oldtidsplastik, Busterne af de romerske Feltherrer og Imperatorer, ogsaa Kvindebillederne fra de kejserlige Familier. Der var en Julia, Augusti filia - tror jeg! altsaa et Kejserbarn fra den mest gyldne Tid. Under sin Haarhjelm med sine Ansigtsliniers Sving og Buer, sin velplantede Hals, havde hun den Frihed der stammer fra en Drøm og et Sejerssmil som Solskin i bølgende Korn. Denne Julia mindede mig oven i Købet om en ung norsk Dame, jeg havde truffet paa mine Rejser, ja gav en vis Forklaring paa det sejrrige i hendes Væsen. Vincis Madonna genkaldte ved sin Ynde en lille, dansk Stivnakke.

Imellem de plastiske Kuriositeter fra Oldtiden tildroges min hedenske og lærde Nyfigenhed ogsaa af Hermafroditen, om hvis Tvillingekøn Romantikerne gjorde sig mange, dybsindige Tanker, og om hvilket Théophile Gautier har skrevet nogle skæmtende Vers.

Den spejlbilledagtige Madonna rystede sin Nakke, som om hendes Fletninger med Aandens evige Liv skulde trodse Hedningekunstens jordvarme Skaberdrømme ...

Saaledes fik jeg et Pust fra evangeliske Snetinder. Det gør intet, at den Madonna er paavist ikke at være af Vinci. Hun forklarer visse Sætninger af ham, som jeg dengang søgte at indprente mig. Og nu genser jeg dette Udtog af Mesterens Kunstbetragtninger med største Overraskelse efter 25 Aars Forløb.

I mange Tilfælde forekommer det den moderne Lyriker som Tanker af hans egen Avl. Her er Ord, som gerne kunde høre hjemme mellem de Indfald, hvormed vi selv overfor en vantro Verden plejer at forsvare den moderne Lyrik. Visse af mine Synspunkter kunde være opstaaede i Leonardo da Vincis Rustkamre, skønt jeg ikke havde sat min Fod der i saa mange Herrens Aar. Jeg har en Fornemmelse af det allestedsnærværende Liv, som røber sig lige klart i de mest ulige Former. I et Digt, som endnu 
ikke er født, skal jeg vise hvorledes man i samme Aandedræt kan nævne »Jordens Blomst og Læbens Tale«.

Den megen selvlærte Filosoferen hos Digterne i vore Dage faar os stundum til at smile, men er kun et Bevis for, at Poesien lever og fornyer sig, idet den gør Fænomenerne levende.

Her er en saadan Tankerække:

Menneskets Aande bevæger Stemmebaandet hørligt for Øret. Jordens Aande giver sig tilkende ved en Udstrømning af Duft, hvoraf vi gennem en anden Sans ligeledes paavirkes.

Lyset, Ilden og Varmen, som vi iagttager med forskellige Sanser, har altid givet Vismændene Paaskud til nyttige Opdagelser og fine Symboler.

Man kan gruble over, hvorvidt Blomsten kun er et Røgelsesfad, eller om den har Lugteorganer ja endog Sans til at skelne sin egen og andres Vellugt. Visse Digtere antyder, at Blomsterne oven i Købet taler. Visse Poeter paastaar, at Ordene, at den menneskelige Veltalenhed har sin egen Sjæl, sin bevidste og levende Magt, der ikke spørger Læben eller Personen om Lov. Det samme lader sig formode om Lyset og Ilden ... er de maaske Udslag af arbejdende Bevidsthed? Jeg mener ikke, at man videnskabeligt kan opnaa noget dermed og finder, at Digtere, der udgiver sig for Videnskabsmænd, som oftest, uden at de selv aner det, ligner Circusnarre paa Stylter. Men umuligt er det ikke, ja slet ikke usandsynligt, at Digteren ved en saadan »genial« Tænken finder det, som mislykkes for den pinlig grublende Forsker.

Poesien er dog paa den sikre Side, naar den nøjes med det rent kunstneriske Udbytte af sin Skarpsynethed. For Leonardo er Sandhed og Kundskab kun Midler til at finde den højeste Skønhed.

Studiet af en dirrende Fuglevinge lærer ham Øjelaagets Bevægelse.

I Bølgeslaget paa Strandbredden ser han et frembrydende Smil.

I Landskabets Himmel finder han et Straaleskær, hvoraf han lærer at male Blikket.

Af at betragte Blomsterne lærer han, hvorledes han skal male Hænderne. Intet findes mellem Himmel og Jord, som Maleren undlader at lære af.

Men Leonardo er en aristokratisk Kunstner. Han omgaas kun de mest udmærkede Mænd, og hvis han tegner en styg og latterlig Type fra Jødegaden, er det blot for Haandelagets Skyld. Efter en saadan Model kan han end ikke fremstille den troløse Judas; thi for at blive optaget i Apostlenes Selskab maatte Forræderen tilhøre en ædlere Kvalitet.

Leonardo sætter en Stolthed i at kunne male Englene, Guds Moder og Gud selv og tager Afstand fra det grove og plumpe hos Malerne fra Nor- 
den. Han fraraader at afbilde Djævelen, da man enten maa gøre ham simpel eller støde Kirken ved at male ham skøn.

Vore Dages Idealister vil næppe begejstres for Vincis Kunst- og Livsopfattelse. Den giver Raad, der grænser tæt til Charlataneri baade i Tekniken og i Omgang med Menneskene. Noget pralende og tvetydigt forefalder denne store Italiener, dels hvor han til Fremstilling af Engle anbefaler en Blanding af de lærde Mænds Dybsind og Kurtisanens søde Smil, dels hvor han giver Anvisning paa at male fornemme Damer og lokke Skønheden frem ved smigrende Ord.

Disse Ateliermetoder vil afskrække en og anden, som i Omgang med Pensel og Farver kun dyrker det ægte, ukonstruerede Væsen. Men Leonardo er en Mester og dybere Tænker end ret mange, der elskede Lærred og Olie. Maaske er der for lidt Smiger i vor grove, pøbelagtige Tid; det kan hænde, at vi alle vilde være bedre, om vore Kunstnere forstod at tale mildt og forelsket til os. Og hvad hans sammenflikkede Engle angaar, da fører han vigtige Grunde i Marken. Han vil ikke male barnagtige, men betydelige Helgenansigter - kun Guds Moder er aldeles uskyldig. Seraferne derimod kender Synden og dens Farve.

Leonardo forstaar en skøn Sjæls guddommelige Ynde, men kender tillige den dobbelte Ynde ved det, som lige antydes, men virkningsfuldt forties.

Det var dette, som gik op for mig paa min første italienske Rejse, da jeg samtidig forsøgte at forstaa Leonardo og en vis kvindelig Gratie, hvis tankevækkende, men erotisk ufrugtbare Væsen ejede noget af Engelens kyske Erfaring og Kurtisanens søde Smil.

Hos denne gamle Maler og denne unge Kvinde, var det mig som om jeg overraskede et Glimt af Fremtidens Ansigt.

Viola var ingen Mona Lisa.

Det underfundige, kvindelige var ikke hendes Sag, nej hun var tilsyneladende den ædleste Frejdighed.

Intet Hovede af Rafaël havde en mere fribaaren og højmodig Holdning. Hun var mystisk og kæk denne Viola, frisk næsten som en forfinet Dreng eller en ung Fyrste.

Jeg har haft megen Ulejlighed med, hvor jeg skulde anbringe hende i Botaniken, om hendes Slægt egentlig var Violerne, eller var det Jordbærrankerne? eller var det en særlig dyrket Art af Rosenfamilien?

En sød og pyntelig Friskhed udstrømmede fra disse Ranker, der ikke bar spiselige Bær.

Jeg opgav dog at analysere hende - Københavnerinden - da jeg ved nogen Tids Overvejelse kom under Vejr med, at hun levede i Eftervirk- 
ningen af sin egen Skønhed. Dette gode og smukke, men noget konstruerede unge Væsen, var som en kvindelig Udgave af hin Homunculus eller Lillemenneske, der skabes i Goethes Faust, som et Kunstprodukt af vor videnskabelige Spekulation.

Om jeg havde kunnet indblæse dette Lillemenneske Livets Aande med stor Taalmodighed, og fri hende ud af hendes Selvbegejstrings-Tilværelse ... det var en Bog at skrive.

\section{Tekstkilder}

Essayet »Leonardo da Vinci« er bevaret i tre manuskriptvarianter: en renskrift (r), en kladde (k) og et udkast (u); alle i Det Kgl. Biblioteks Ny Kongelig Samling (NKS). Tekstgrundlaget udgøres her af renskriften. Rettelser er så vidt muligt dokumenteret i de øvrige kilder.

r NKS 2175, 2, I [læg: »Leonardo da Vinci«]. Udateret. Fremmed hånd.

k NKS 2175, 2, I [læg: »Leonardo da Vinci«]. Udateret.

u NKS 1340, $8^{\circ}$ [notesbog: 74]. Teksten udateret. Notesbogen dateret: »Marts 1918«.

\section{Tekstrettelser}

Generelt: Renskriftens understregninger er her gennemgående gengivet med kursiv.

s. 183, 1. 24 Museer. < Museer; således k og u

s. 183, 1. 30 Uffizierne < Ufficierne; således u; k har: Uffi[ulæselig rettelse]ierne]

s. 183, 1. 31 rennæssancefrom - < rennæssancefrom; såleds k; u har: renæssancehedensk

s. 184, 1. 9 Aandsbevidsthed < Aandsbevisthed; således k; optræder ikke i u

s. 184, 1.28 evangeliske Snetinder < evangeliske Snetinde; k har: en evangelisk Snetinde; $u$ har: en evangelisk Gletcher

s. $184,1.38$ Aar. < Aar

s. $185,1.2$ Tale «. $<$ Tale « 
s. $185,1.10$ Ilden og < Ilden; således k og u

s. $185,1.10$ iagttager < iagtager; således k; optræder ikke i u

s. $185,1.11$ til < til til; således k; optræder ikke i u

s. $185,1.14$ Visse < visse; optræder ikke i u

s. 186, 1.19 guddommelige < guddommelig; således k og u

s. 186, 1. 31 mystisk < mystik; således k og u

\section{Litteratur}

Claussen, Sophus: Antonius i Paris. Valfart. Danske Klassikere, v. Jørgen Hunosøe og Esther Kielberg, DSL / Borgen, 1990

Claussen, Sophus: Foraarstaler, Gyldendal, 1927

Claussen, Sophus: Heroica. Sophus Claussens Lyrik VI, v. Jørgen Hunosøe, Gyldendal, 1983

Claussen, Sophus: Løvetandsfnug, Gyldendal, 1918

Frandsen, Ernst: Sophus Claussen, bind 1-2, Gyldendal, 1950

Henriksen, Aage: »Pavens Madonna«, Det guddommelig barn og andre essays om Karen Blixen, Gyldendal, 1965, s. 105-148

Jørgensen, Bo Hakon og Jan Sand Sørensen: Sophus Claussen. En studiebog, Gyldendal, 1977

Rigoni, Cesare: Catalogo della R. Galleria degli Uffizi in Firenze, Tip. Cooperativa, 1891

Ringgaard, Dan: Den poetiske laekage. Sophus Claussens lyrik, rejsebøger og essayistik, Museum Tusculanums Forlag, 2000

Sørensen, Peer E.: »Mellem konfession, autobiografi og roman - en prismatisk fortælling «, Povl Schmidt m.fl. (red): Lcesninger $i$ dansk litteratur, bind 1-5, Odense Universitetsforlag, 1998, bind 1, s. 245-261

Zeruneith, Keld: Fra klodens varksted. En biografi om Sophus Claussen, Gyldendal, 1992 